\title{
Sofrimento psíquico e trabalho de profissionais de enfermagem ${ }^{1}$
}

\author{
Jadir Camargo Lemos \\ Roberto Moraes Cruz \\ Silvio Paulo Botomé \\ Universidade Federal de Santa Catarina
}

$\mathrm{C}$ omo justificar que, mesmo sofrendo, os trabalhado res de enfermagem que atuam em unidades críticas continuam trabalhando? Como eles toleram o sofrimento? Como eles administram as adversidades ocorridas durante a jornada de trabalho? Essas perguntas encontram respostas no decorrer da leitura da tese de doutorado da enfermeira Carmem Lúcia Colomé Beck, docente do Departamento de Enfermagem da UFSM, escrita e defendida, no ano de 2000, junto ao Curso de Doutorado em Filosofia da Enfermagem da UFSC, intitulada Da banalização do sofrimento à sua re-significação ética na organização do trabalho ${ }^{l}$.

O estudo é caracterizado pela autora como uma investigação da área humano-social, estruturada a partir de uma abordagem qualitativa do tipo exploratório-descritiva. Os participantes foram 46 trabalhadores das equipes de enfermagem de unidades críticas de dois hospitais da cidade de Santa Maria, interior do Rio Grande do Sul. Nesse trabalho, a autora problematiza os efeitos que a organização do trabalho e os eventos situacionais provocam na vida desses trabalhadores, demonstrando que "a organização do trabalho, bem como os eventos situacionais específicos, decodificados ou não, vivenciados individual ou coletivamente, em unidades críticas, produzem efeitos sobre o modo de enfrentamento do sofrimento" (Beck, 2000, p. 228).

Os temas instituição hospitalar, trabalho, processos de trabalho (principalmente em unidades consideradas críticas) e eventos situacionais com os quais se deparam e são vividos pelos trabalhadores da equipe de enfermagem que atuam nessas unidades, são objetos de discussão a partir de Marx (1968), Taylor (1992), Lima (1993), Dejours (1994), Leopardi (1994), Sampaio (1995) e Gonzales (1995). Para examinar o papel social da Enfermagem e o estado de alerta e a banalização do sofrimento em unidades críticas, a autora apoiou-se, principalmente, nos escritos de Moscovici (1997), Pitta (1994), Taylor (1992), Dejours (1992, 1994 e 1999), Silva (1998) e Lopes (1995). A historicidade das instituições hospitalares é resgatada com base em Foucault (1996) e Pitta (1994).

Beck usa como situação de pesquisa dois hospitais, um privado e outro público, o segundo caracterizado como hospital escola e referência regional, a autora compõe o grupo de sujeitos com 46 trabalhadores: enfermeiros, técnicos e auxiliares de enfermagem, dos quais 25 pertencem ao quadro de funcionários de um dos hospitais e 21 do outro. Nesses hospitais foram selecionadas as seguintes unidades: CTI adulto, centro cirúrgico, pronto atendimento, unidade de internação clínica onco-hematológica e ambulatório de oncohematologia, consideradas críticas por serem as unidades com maior probabilidade de ocorrência de eventos como óbito, informações sobre óbito aos familiares, internações, altas e pacientes em situação de urgência/emergência.

Os instrumentos de coleta de dados utilizados foram: questionário contendo perguntas fechadas para detectar como o enfermeiro ou o auxiliar de enfermagem se sentia ao assumir o plantão, roteiro de observação direta, feita no decorrer do plantão, com registro em anotações de campo e entrevista semi-estruturada, com questões abertas, conduzida pela pesquisadora. A coleta dos dados foi efetuada no período de novembro de 1998 a junho de 1999, envolvendo três turnos de trabalho nos dois hospitais.

As informações colhidas foram analisadas em grupo único, envolvendo os trabalhadores dos dois hospitais. Os dados pessoais foram computados e apresentados em tabelas nas quais aparecem separadamente os enfermeiros e os auxiliares de enfermagem. Os sinais vitais foram registrados no início e no final do plantão com o objetivo de compará-los posteriormente. Os dados obtidos nas entrevistas foram compilados para caracterizar o estado emocional dos trabalhadores. As observações seguiram um roteiro padrão para todas as unidades e foram feitas para obter dados sobre como os trabalhadores se portavam frente à ocorrência de eventos situacionais. As entrevistas foram analisadas mediante leitura exaustiva para delimitação do seu significado e, posteriormente, as respostas foram agrupadas mediante "semelhanças e diferenças" (Beck, 2000, p. 85).

Ao apresentar os resultados, a pesquisadora caracteriza as unidades críticas e os processos de trabalho nelas realizados, selecionando pontos comuns entre elas. Pontos que, analisados, denotam fatores que mobilizam sentimentos e que provocam alterações nos estados emocionais nos trabalhadores. Também entre esses pontos são possíveis de serem identificados alguns fatores inerentes à própria personalidade do trabalhador e outros da organização do trabalho. A caracterização dos processos de trabalho nas diversas unidades estudadas aponta para a existência de cargas físicas e 
psíquicas, corroborando com estudos anteriores de Dejours (1994) que afirmam que todo trabalho tem uma determinada carga, fortalecendo a idéia da existência de carga psíquica nos processos de trabalho descritos.

A amostra, predominantemente feminina (95\%), é composta de 20 enfermeiros, um técnico e 25 auxiliares de enfermagem, totalizando 46 trabalhadores. Foi verificado que $85 \%$ dos enfermeiros e $73 \%$ dos auxiliares têm entre um e 10 anos de trabalho nos respectivos hospitais, que $40 \%$ dos enfermeiros e somente $8 \%$ dos auxiliares têm dois empregos e que $65 \%$ dos trabalhadores estão situados na faixa compreendida entre 30 e 40 anos de idade.

As respostas obtidas nos questionários e nas entrevistas, bem como tudo o que foi observado, passam por uma análise depurada com uma discussão embasada teoricamente em Pitta (1994), quando descreve as unidades críticas dos dois hospitais; em Dejours (1999), ao descrever sofrimento e mecanismos de defesa utilizados por aqueles trabalhadores; em Silva (1998), para comentar as doenças mais citadas e as situações estressantes dos trabalhadores da Enfermagem; em Codo, Sampaio e Hitomi (1993) e Lima (1993), para interpretar os dados sobre eventos situacionais.

A análise das respostas dos entrevistados evidenciou o sofrimento daqueles trabalhadores. Fatores inerentes à organização do trabalho, tais como a falta de condições materiais para prestação de assistência com qualidade e de recursos humanos, são citados como causadores de desconforto e sofrimento. Contudo, como compete ao trabalhador prestar assistência independente das condições de trabalho, o estudo aponta para a utilização de mecanismos de defesa, mesmo que usados inconscientemente, como a negação, a sublimação e a banalização do sofrimento, da assistência e até das informações prestadas aos pacientes e seus familiares.

As observações de campo realizadas permitem identificar, por meio dos instrumentos elaborados, o sofrimento e os mecanismos de defesa utilizados pelos trabalhadores para suportar ou minimizar as adversidades ocorridas em seus cotidianos. Entre os resultados encontrados, alguns contrariaram as expectativas do estudo, mas, de maneira geral, foi possível concluir que, diante do sofrimento, os trabalhadores manifestam-se utilizando mecanismos de defesa (individual ou coletivamente). Por outro lado, de suas informações é possível depreender a negação da existência do sofrimento, embora o banalizem invariavelmente, tentando dar-lhe um ar de naturalidade como se tudo fizesse parte da rotina do trabalho.

Expressões como "isto é natural na unidade", "faz parte da rotina", "um morre outro vem", ou o fato dos trabalhadores usarem o pronome "tu" para falar dos seus próprios sentimentos sinalizam aspectos dessa negação ou banalização do sofrimento no trabalho. No entanto, ao optarem por trabalhar com pacientes, os trabalhadores possivelmente assumem um compromisso ético que os obriga a agir dessa forma. $\mathrm{O}$ fato de ter que re-significar a ética na organização do traba- lho ocorre, dessa forma, porque é precisam de um novo significado ou o atual já não contempla as necessidades das pessoas envolvidas nessa situação.

Ao atingir os objetivos propostos e confirmar a tese defendida, o estudo mostra relevância científica, pois constitui um acréscimo ao conhecimento existente, além de contribuir socialmente ao partilhar a compreensão sobre os problemas que envolvem a relação entre a organização do trabalho, a saúde e a vida dos trabalhadores de Enfermagem.

Com uma linguagem clara e precisa, a obra é destinada mais especificamente àquelas pessoas ligadas à área de saúde e trabalho, ao mesmo tempo em que permite ao leigo uma compreensão bastante clara da realidade vivida por aqueles trabalhadores, que lutam não apenas para garantir sua sobrevivência, mas também pela dignidade da categoria.

\section{Referências}

Beck, C. L. C. (2000). Da banalização do sofrimento à sua re-significação ética na organização do trabalho. Tese de doutorado não-publicada. Universidade Federal de Santa Catarina, Florianópolis.

Codo, W., Sampaio, J. J. C., \& Hitomi, A.H. (1993). Individuo, trabalho e sofrimento: uma abordagem interdisciplinar. Petrópolis: Vozes.

Dejours, C. (1992). A loucura do trabalho: estudos de psicopatologia do trabalho. São Paulo: Cortez.

Dejours, C. (1999). A banalização da injustiça social. Rio de Janeiro: FGV.

Dejours, C., Abdouchelli, E., \& Jayet, C. (1994). Psicodinâmica do trabalho: contribuições da escola dejouriana à análise da relação prazer, sofrimento e trabalho. São Paulo: Atlas.

Foucault, M. (1996). Microfisica do poder. Rio de Janeiro: Graal.

Gonzales, R. M. B. (1995). Na busca da auto-percepção: um trajeto vivenciado por enfermeiras. Dissertação de mestrado não-publicada. Universidade $\mathrm{Fe}$ deral de Santa Catarina, Florianópolis.

Leopardi, M. T. (1994, outubro/novembro). Qualidade de vida no trabalho: a busca de um trabalho omnilateral. Trabalho apresentado no Congresso Brasileiro de Enfermagem, Porto Alegre.

Lima, M. G. (1993). Assistência prestada pelo enfermeiro em UTIs: aspectos afetivos e relacionais. Dissertação de mestrado não-publicada. Escola de Enfermagem de Ribeirão Preto, Ribeirão Preto.

Lopes, M. J. M. (1995). Maneiras de cuidar, maneiras de ensinar: a enfermagem entre a escola e a prática profissional. Porto Alegre: Artes Médicas.

Marx, K. (1968). O capital: crítica da economia política. Rio de Janeiro: Civilização Brasileira.

Moscovici, F. (1997). Razão e emoção: a inteligência emocional em questão. Salvador: Casa de Qualidade.

Pitta, A. (1994). Hospital: dor e morte como oficio. São Paulo: Hucitec.

Sampaio, J. J. C., Hitomi, A., \& Ruiz, E. M. (1995). Saúde e trabalho: uma abordagem do processo e jornada de trabalho. In W. Codo \& J. J. C. Sampaio (Orgs.), Sofrimento psíquico nas organizações: saúde mental e trabalho (p. 65-84). Petrópolis: Vozes.

Silva, M. J. P. (1998). Reflexões sobre a relação interpessoal no cuidar: o fator corpo entre a enfermeira e o paciente. In D. E. Meyer, V. R. Waldow \& M. J. M. Lopes (Orgs.), Marcas da diversidade: saberes e fazeres da enfermagem contemporânea (pp. 127-135). Porto Alegre: Artmed.

Taylor, C. M. (1992). Fundamentos de enfermagem psiquiátrica. Porto Alegre: Artes Médicas. 
Nota

1 Resenha da tese de doutorado "Da banalização do sofrimento à sua re-significação ética na organização do trabalho" de Carmem Lúcia Colomé Beck, defendida junto ao Doutorado em Filosofia da Enfermagem da Universidade Federal de Santa Catarina, SC, no ano de 2000.

Jadir Camargo Lemos, mestre em Psicologia pela Universidade Federal de Santa Catarina (SC), é professor do Departamento de Fisioterapia da Universidade Federal de Santa Maria, RS.

Roberto Moraes Cruz, doutor em Engenharia de Produção pela Universidade Federal de Santa Catarina (SC), é professor do Departamento de Psicologia da Universidade Federal de Santa Catarina, SC.

Silvio Paulo Botomé, doutor em Psicologia pela Universidade de São Paulo, é professor do Departamento de Psicologia da Universidade Federal de Santa Catarina, SC.

Endereço para correspondência: Jadir Camargo Lemos, Universidade Federal de Santa Maria, Centro de Ciências da Saúde, Departamento de Fisioterapia e Reabilitação - UFSM, Av Rondônia S/N, Camobi 97000001, Santa Maria, RS. E-mails: [JCL] jadircl@bol.com.br; [RMC] rcruz@cfh.ufsc.br; [SPB] botome@cfh.ufsc.br. 